\title{
VALIDATION AND USABILITY OF AIDMED \\ - TELEMEDICAL SYSTEM FOR CARDIOLOGICAL \\ AND PULMONARY DISEASES
}

ŁUKASZ CZEKAJ

AIDMED, sp. z o.o.

ul. Uphagena 27/702, 80-237 Gdańsk, Poland

e-mail address: lukasz.czekaj@aidlab.com

ORCID: 0000-0002-8920-6552

JAKUB DOMASZEWICZ

AIDMED, sp. z o.o.

ul. Uphagena 27/702, 80-237 Gdańsk, Poland e-mail address: jdomaszewicz@aidmed.ai ORCID: 0000-0003-2220-789X

ŁUKASZ RADZIŃSKI

AIDMED, sp. z o.o.

ul. Uphagena 27/702, 80-237 Gdańsk, Poland e-mail address: lukasz.radzinski@aidlab.com ORCID: 0000-0002-6367-1130

ANDRZEJ JARYNOWSKI

Interdisciplinary Research Institute

Oriona 15/8, 67-200 Głogów, Poland

e-mail address: ajarynowski@gmail.com

ORCID: 0000-0003-0949-6674

ROBERT KITEOWSKI

AIDMED, sp. z o.o.

ul. Uphagena 27/702, 80-237 Gdańsk, Poland e-mail address: robert@aidmed.ai

ORCID 0000-0001-7237-8051

\section{AnNA DoBOsZYŃSKA}

Pulmonology Department, University of Warmia and Mazury

ul. Jagiellonska 78, 11-041 Olsztyn, Poland e-mail address: anna.doboszynska@uwm.edu.pl

ORCID: 0000-0001-9817-5287 


\begin{abstract}
Aim The aim of this paper is to present the results of the validation of AIDMED as a telemedical system, i.e. its capability in faithful registration of biomedical signals, its acquisition in a telemedical scenario and its representation in online application. Usability of such a tool for a dedicated population was also assessed.

Methods We describe and discuss functionalities provided by AIDMED. We perform a series of experiments where we measure biological signals with AIDMED and with a reference device. We provide statistical analysis of experiments. We also compare the functionality of AIDMED with other similar solutions. We discuss the usability of AIDMED in tele observation of COVID-19 patients.

Results We show diagnostic equivalence of AIDMED device and reference devices. Moreover, we indicate advantages of AIDMED system (as task management and patient's feedback via mobile app) for at home telemonitoring in comparison to standard of care.

Conclusions AIDMED system provides an integrated platform which enables observation of COVID-19, cardiological and pulmonary patients and many more. Thus, an opportunity for both better quality of care and better subjective patient satisfaction with use of AIDMED has got a solid foundation.
\end{abstract}

Key words: telemedicine, m-health, e-health, COVID-19

\title{
INTRODUCTION
}

Remote monitoring of patient health is widely used for pulmonological (Duplaga, 2019) and cardiological diseases (Scalvini, Comini, Bernocchi, 2020), which are major burdens for health care systems in developed countries. Implementation of ongoing remote monitoring (performed on a relatively continuous basis) of patients at home has been more and more popular due to the COVID19 pandemic (Wong, et al., 2021). One barrier in countries such as Poland was low e-health literacy among both patients and medical personnel. Both groups are usually elderly and were not convinced to apply ICT solutions in medical practice (Duplaga, 2021). Thus, using novel technologies with smartphones was not a trivial case for at-risk elderly patients. In recent years, on-line wearable solutions have been mainly covering areas of lifestyle applications and were less widely applicable in the non-research medical practice (Overdijkink, et al., 2018). AIDLAB sensors (predecessor of AIDMED) measure user activity, heart ECG, burned calories, respiration or skin temperature for instance during exercises for live biofeedback on smartphones (Czekaj, et al., 2020; Radziński, et al., 2020). The target population of AIDLAB is young and well-educated so-called "digital tribes" (Taranowicz, 2010). As a result of the pandemic, many patients and healthcare providers were forced to use telemedicine. Although there were many skeptics and fears, at the end of the day, they found that technology can really improve healthcare (Beier, Kocher, Roy, 2020). The growing role of the Internet in providing access to health services (in most common sense as teleconsultations as well as dedicated e-health solutions) during the COVID-19 pandemic has been recognised as one of the key determinants of wellbeing (Duplaga, 2021). Availability of the Inter- 
net and popularisation of IT skills (especially during COVID-19 pandemic) has accelerated expansion of the scope of telemedicine for the average patient (even older people). In this article, we present the opportunities provided by using the Internet in patient self-monitoring with digital health AIDMED technology for pulmonological, cardiological and other diseases. We describe an ongoing medical trial where AIDMED is used in tele observation of COVID - 19 patients. Combination of mobile health (mHealth) as well as wearable and portable sensors is well-positioned by AIDMED to increase the quality of care, patient satisfaction and prevention of overloading of the healthcare system through at-home screening, diagnosis, and monitoring.

\section{COVID-19 CLINICAL TRIAL}

AIDMED is used in an ongoing clinical study whose aim is to build and validate the telemedical system in the purpose of optimization of COVID-19 patient management. This dedicated group is asymptomatic and mildly symptomatic patients for which there is no need for hospitalisation at the moment of medical examination, however because of other ailments (e.g. comorbid diseases) there is risk of rapid deterioration. Possibility of remote observation during at home management may significantly relieve the health system while maintaining healthcare quality, hospitalisations and patient quality of life.

During clinical study a large longitudinal dataset is collected from COVID19 patients and from patients with pulmonary and cardiological diseases. Data set consists of biosignals (time series) and questionnaires. Patients are asked to perform various tasks like breathing exercise or signal recording during and after physical effort.

AIDMED is used for biosignal acquisition, presentation and interpretation. Important adaptation of the system for the purpose of the clinical study was supporting interaction with patients in terms of user tasks.

Since a large group of patients is elder people not familiar with smartphone and electronic devices, an important part of the system design was to ensure easeof-use. Patients are qualified for the trial during ordinary medical examination, therefore another goal was to provide an easy and fast process of qualification.

We propose following process of patient qualification and management during clinical study:

1) install application AIDMED ONE; user obtain short code from personnel; that code enables login in AIDMED ONE and to connect acquired signal with specific patient;

2) provide health information according to doctor needs (e.g. qualification questionnaire) and undergo clinical investigation (there are several type of examination e.g. apnea, holter ecg, covid);

3) patients are trained how to wear and use AIDMED (which was designed to be as simple as possible) or such information is given in video tutorial/user guide; 
4) patients register signals with AIDMED ONE at home (or other place they stay) and perform tasks assigned: registration at rest, signal registration during exercises, questionnaire, training (e.g. breathing training); tasks are scheduled at specific hours and there are notifications about coming or overdue tasks.

Detailed presentation of the system components with focus on the clinical study is provided in further parts of the paper.

\section{AIDMED - System to Measure Patient Vital Signs}

AIDMED system is a certified medical solution (TÜV NORD, 2021) for diagnostics support in case of sleep apnea and arrhythmia for adult patients. The system is intended for long term use at home: an examination may take more than 14 days and may be performed in a continuous manner. It is designed for fully remote data acquisition in nearly real time.

\section{AIDMED ONE recorder - a portable medical device}

AIDMED ONE (together with pulse oximeter) is equipped with following sensors:

1) bioimpedance sensor for measuring chest volume changes;

2) accelerometer sensor for body position and patient activity monitoring;

3) pressure sensor for measuring airflow through nose or mouth-nose;

4) skin-contact thermometer for measuring chest temperature;

5) microphone for volume level registration (cough and snore detection);

6) single lead ECG sensor;

7) $\mathrm{SpO} 2$ sensor which measures saturation level (as an additional device see Fig, 1b). All these signals are considered as useful in observation of COVID-19 patients.

AIDMED ONE provides functionality of "user event": user may indicate occurrence of important rare symptoms like heart palpitation.

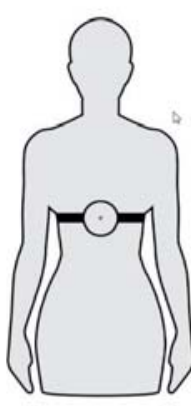

a)

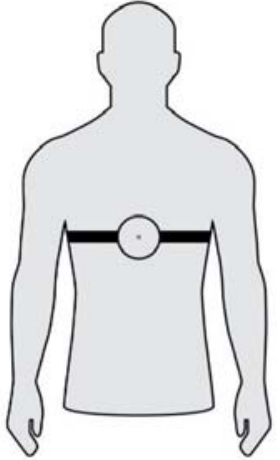

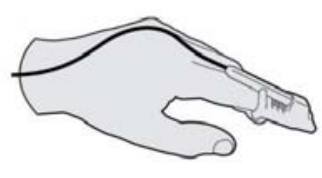

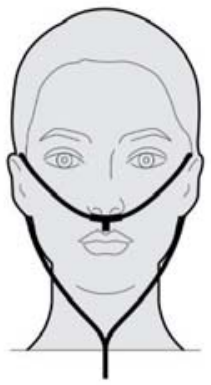

c)

Fig. 1. Wearing of ADIMED ONE recorder: a) recorder position on the chest strap; b) pulse oximeter sensor on finger; c) wearing nasal cannula.

Source: own graphic 
Recorded data is reliably retransmitted from AIDMED ONE to AIDMED HEALTH (mobile application) using Bluetooth Low Energy (BLE) protocol and then to AIDMED CLOUD through the internet.

\section{Mobile App - AIDMED HEALTH}

The application provides signal overview (for simple verification of signal quality and proper wearing of the recorder) and interaction between patients and doctors. The interaction is supported by the user tasks, e.g.: i) data acquisition at rest; ii) data acquisition during exercise; iii) training supporting rehabilitation (e.g. breathing exercises); iv) questionnaire (e.g. patient is asked to provide information about health state self assessment, breathing problems etc).

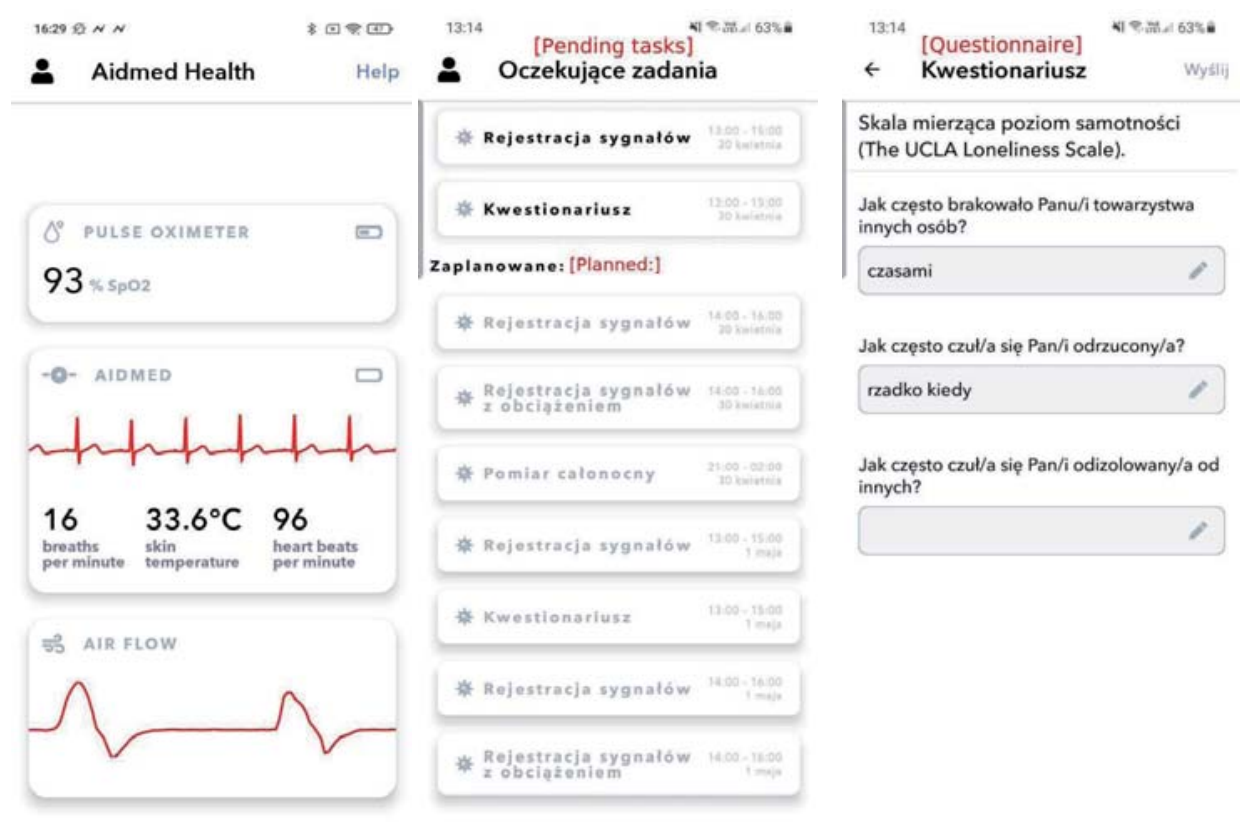

Fig. 2. AIDMED HEALTH: a) signals overview; b) user tasks; c) questionnaire. As the application is intended mainly for patients in Poland, the user tasks and the questionnaire are currently available only in Polish. The English translation is written in red.

Source: own graphic

Patient Performance (Unsupervised or Partially Supervised)

Configuration of the system for a patient is minimal and simplified. Registrator AIDMED ONE seems to be easy to use and comfortable. Instructions (given by medical personnel, printed or in textual/video in AIDMED HEALTH mobile app) are supposed to be easy to understand (Hernández-Neuta, et al., 2020). The system is designed to be used by various at-risk patients (as elderly) in their homes (or 
other place of residence) with only minimum professional supervision from teleconsultant only.

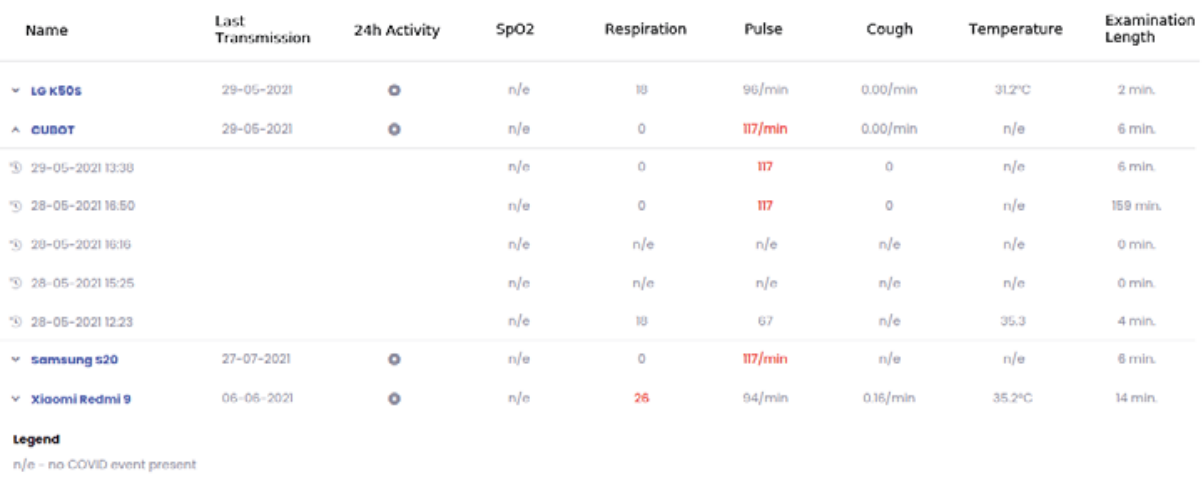

Fig. 3. AIDMED CLOUD: summary report for cohort of patients.

Source: own graphic

\section{Analytical Platform - AIDMED CLOUD}

Telemedical platform AIDMED CLOUD is a place where acquired signals are presented and analysed. Personnel may observe registered signals in nearly real-time (with 1 minute lag); personnel have information about last signal recording; systems provide summary information about patients (see Fig. 3). Doctors or health specialists view the whole signal; perform analytics (e.g. automatic detection of events like desaturation) and generate reports from examination (see Fig. 4).

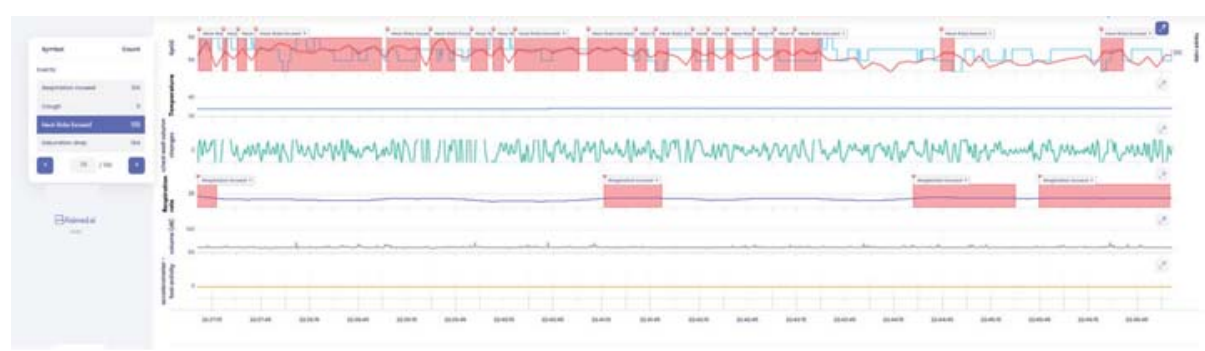

Fig. 4. AIDMED CLOUD: detailed view from examination.

Source: own graphic

\section{Methods/materials}

Here we focus on validation of AIDMED system as a device which supports telediagnostics of sleep apnea and arrhythmia. For this purpose we validate acquisition of signals related to chest volume changes, airflow through the nose or mouth-nose, and ECG. We perform simultaneous registration of given signals from AIDMED ONE and a reference device (both reference devices are medical devices): 
- for chest volume changes (respiration) and airflow it was Alice NightOne (which can be used in home under control, however signals are not available online);

- for ECG it was Compumedics Somte-PSG (which is used mainly in out-patients settings due to complicated wearing procedure).

In validation of chest volume changes and airflow we gathered signals from 5 volunteers and ECG from 3 volunteers (see Table 1).

Table 1

Subjects involved in validation of AIDMED in Respiration context (first three have been checked for ecg too)

\begin{tabular}{lllllll}
\hline No. & sex & age & $\begin{array}{l}\text { weight } \\
{[\mathrm{kg}]}\end{array}$ & $\begin{array}{l}\text { height } \\
{[\mathrm{cm}]}\end{array}$ & $\begin{array}{l}\text { numb. } \\
\text { of exam. } \\
\text { resp. }\end{array}$ & $\begin{array}{l}\text { numb. of } \\
\text { exam. ECG }\end{array}$ \\
\hline 1 & M & 38 & 74 & 176 & 2 & 1 \\
2 & $\mathrm{M}$ & 25 & 70 & 180 & 1 & 1 \\
3 & $\mathrm{~K}$ & 22 & 60 & 175 & 2 & - \\
4 & $\mathrm{M}$ & 21 & 90 & 180 & 1 & - \\
5 & $\mathrm{M}$ & 31 & 79 & 194 & 1 & 1 \\
\hline
\end{tabular}

Source: own research.

Combination of activity tasks managing technologies on mobile phone with portable biosignal recording devices (with validated diagnostic power) dedicated for at-risk population is going to be archived for AIDMED system. Thus, we are going to investigate possible gaps in already implemented projects and products offered in Poland (GOV.PL, 2020). Vast majority of solutions available on the market with sensors mentioned above:

- which allows functional physiological tests such as jumps, running, etc. are dedicated to a healthy population only;

- which are dedicated to elderly, do not support scheduling and functional tests on their own (Liu, et al., 2016)

Moreover, there are only limited studies on solutions used in elderly population using this kind of automatic sensor in unsupervised physiological tests (Cebo, et al., 2020). We found that an interactive approach to a patient is still missing in telemedical solutions measuring ECG and respiratory variables and mostly lifestyle application allows for it (however they do not collect professional physiological signals). Thus, additional non-clinical assets of AIDMED is going to be analysed.

\section{Results}

Validation of chest volume changes

Data set was summarised in Table3 (data length, mean respiration rate). AIDMED ONE uses a bioimpedance method for estimation of chest volume change while 
Alice NightOne uses elastic chest belt. These signals differ significantly because of different physical backgrounds (as it is reflected in low correlation coefficient for raw signals, see Table 2). Both methods are clinically valid (Seppä, Hyttinen, Viik, 2015; Scott, Kaur, 2020). Therefore we compare devices in terms of respiration rate (RR) time series. Respiration rate is calculated as a number of peaks in 1 minute block. Then we compare block to block and calculate statistics like mean absolute error in respiration rate and root mean square error for respiration rate. We observe high correlation between respiration rate series $(\mathrm{R}>80 \%)$.

\section{Validation of airflow}

Dataset was summarised in table 3. Both devices record signals using the same method: dynamic pressure measurement. Examples of signals are depicted on Fig. 5 . Accordance of raw signals is very high ( $\mathrm{R}>80 \%)$. As in the validation of the chest volume, we compare respiration rate (RR) calculated on the base of airflow. We get correlation $\mathrm{R} \sim 99 \%$.

Table 2

Summary of chest volume changes validation

\begin{tabular}{lccccccc}
\hline No. & $\begin{array}{c}\text { exam. } \\
\text { time [s] }\end{array}$ & $\begin{array}{c}\text { corr. coef. } \\
\text { for raw } \\
\text { signals } \\
(\mathrm{R})\end{array}$ & $\begin{array}{c}\text { corr. coef } \\
\text { for RR (R) }\end{array}$ & $\begin{array}{c}\text { mean RR } \\
\text { Aidmed } \\
\text { One }[1 / \\
\text { min] }\end{array}$ & $\begin{array}{c}\text { mean RR } \\
\text { Alice } \\
\text { NightOne } \\
{[1 / \mathrm{min}]}\end{array}$ & $\begin{array}{c}\text { mean } \\
\text { absolute } \\
\text { error RR } \\
{[1 / \mathrm{min}]}\end{array}$ & $\begin{array}{c}\text { root mean } \\
\text { square } \\
\text { error RR } \\
{[1 / \mathrm{min}]}\end{array}$ \\
\hline $1 \mathrm{a}$ & 1050 & 0.48 & 0.94 & 14.8 & 13.1 & 1.9 & 2.3 \\
$1 \mathrm{~b}$ & 1290 & 0.44 & 0.80 & 14.4 & 13.7 & 3.4 & 4.2 \\
2 & 1830 & 0.69 & 0.97 & 15.2 & 14.4 & 1.2 & 1.6 \\
$3 \mathrm{a}$ & 870 & 0.57 & 0.90 & 10.9 & 10.2 & 1.7 & 2.0 \\
$3 \mathrm{~b}$ & 990 & 0.45 & 0.85 & 21.5 & 20.4 & 4.8 & 5.8 \\
4 & 1890 & 0.69 & 0.97 & 15.3 & 14.7 & 1.1 & 1.5 \\
5 & 1470 & 0.36 & 0.89 & 11.8 & 11.2 & 1.4 & 2.2 \\
\hline
\end{tabular}

Source: own research.

Table 3

Summary of nasal airflow validation

\begin{tabular}{|c|c|c|c|c|c|c|c|}
\hline No. & $\begin{array}{l}\text { exam. } \\
\text { time }[\mathrm{s}]\end{array}$ & $\begin{array}{l}\text { corr. coef. } \\
\text { for raw } \\
\text { signals } \\
\text { (R) }\end{array}$ & $\begin{array}{l}\text { corr. coef } \\
\text { for RR (R) }\end{array}$ & $\begin{array}{l}\text { mean RR } \\
\text { Aidmed } \\
\text { One [1/ } \\
\text { min] }\end{array}$ & $\begin{array}{l}\text { mean RR } \\
\text { Alice } \\
\text { NightOne } \\
{[1 / \mathrm{min}]}\end{array}$ & $\begin{array}{l}\text { mean } \\
\text { absolute } \\
\text { error RR } \\
{[1 / \mathrm{min}]}\end{array}$ & $\begin{array}{l}\text { root mean } \\
\text { square } \\
\text { error RR } \\
{[1 / \mathrm{min}]}\end{array}$ \\
\hline $1 \mathrm{a}$ & 1115 & 0.91 & 0.99 & 16.37 & 16.16 & 0.32 & 0.77 \\
\hline $1 b$ & 1310 & 0.93 & 0.99 & 17.27 & 17.09 & 0.45 & 0.78 \\
\hline 2 & 1800 & 0.81 & 0.99 & 16.60 & 16.80 & 0.47 & 0.79 \\
\hline $3 a$ & 923 & 0.94 & 0.99 & 12.38 & 12.69 & 0.31 & 0.58 \\
\hline $3 b$ & 1020 & 0.90 & 1.00 & 23.18 & 23.18 & 0.12 & 0.34 \\
\hline 4 & 1640 & 0.83 & 1.00 & 19.46 & 19.61 & 0.29 & 0.58 \\
\hline \multirow[t]{2}{*}{5} & 1467 & 0.84 & 0.98 & 14.00 & 13.84 & 0.48 & 0.78 \\
\hline & 1325 & 0.88 & 0.99 & 17.04 & 17.05 & 0.35 & 0.66 \\
\hline
\end{tabular}

Source: own research 


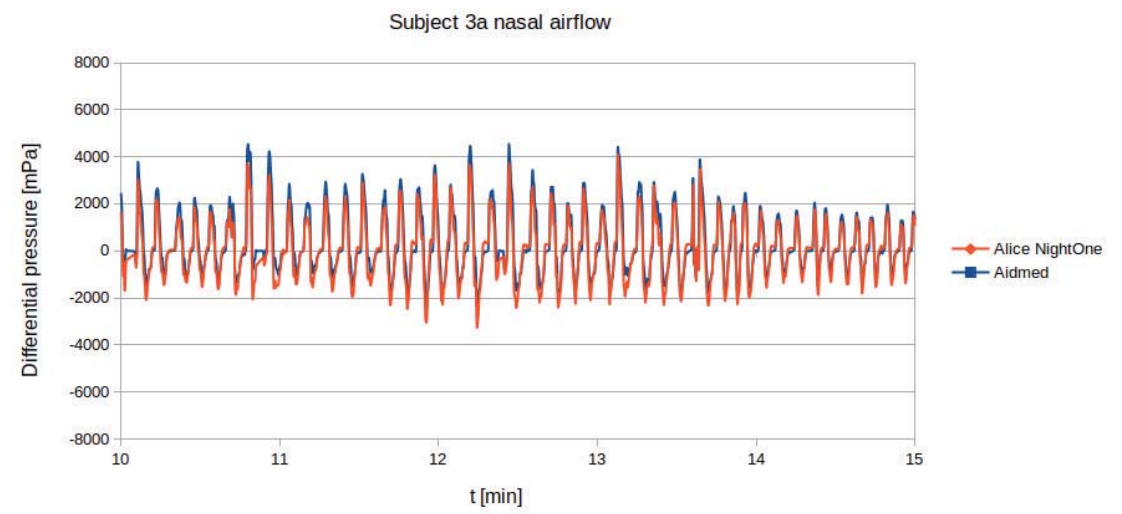

Fig. 5. Dynamic pressure (nasal airflow): example signals comparison.

Source: own research

\section{Validation of ECG}

First we reviewed the accordance of raw signals. To get a stable reference signal we use a phantom generator. For both signals the same filtration method was applied. As one can see in Fig. 6, acquired signals are indistinguishable. Sample signal registered from volunteer is depicted in Fig. 7. The signals are not identical since electrode placement differs due to physical reasons. Morphological waves PQRST are well visible.

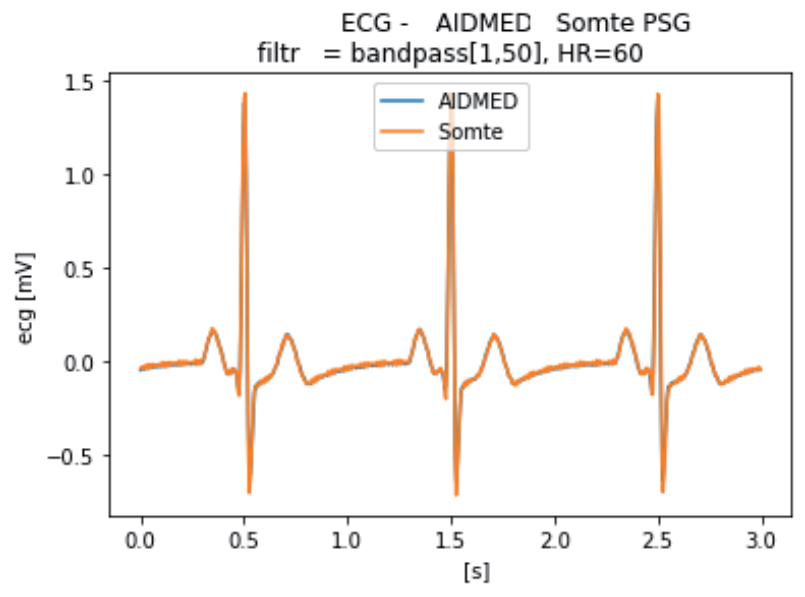

Fig. 6. ECG registered from phantom generator: example signals comparison.

Source: own research

Further we compare heart rate (HR) time series calculated on the base of ECG. We use the Hamilton algorithm for the purpose of the QRS detection. HR time series indexed by the QRS complex (RR index) are depicted in Fig. 7. We observe 
high correlation in HR time series from both devices. We compare QRS detection and QRS interval in table 4. Observed HR time series have high accordance.

Table 4

Summary of ECG validation: QRS detection and heart rate comparison

\begin{tabular}{lllllll}
\hline Subject & $\begin{array}{l}\text { exam. } \\
\text { time }\end{array}$ & $\begin{array}{l}\text { bias of QRS } \\
\text { location [s] }\end{array}$ & $\begin{array}{l}\text { root mean } \\
\text { square error } \\
\text { of QRS } \\
\text { location [s] }\end{array}$ & $\begin{array}{l}\text { corr. coeff. } \\
\text { for HR (R) }\end{array}$ & $\begin{array}{l}\text { bias of HR } \\
{[1 / \mathrm{min}]}\end{array}$ & $\begin{array}{l}\text { root mean } \\
\text { square error } \\
\text { of HR [1/min] }\end{array}$ \\
\hline 1 & 210 & 0 & $<0.01$ & 0.994 & -0.12 & 0.36 \\
2 & 103 & 0 & 0.01 & 0.972 & -0.09 & 1.66 \\
5 & 286 & 0 & 0.01 & 0.987 & -0.13 & 0.63 \\
\hline
\end{tabular}

Source: own research
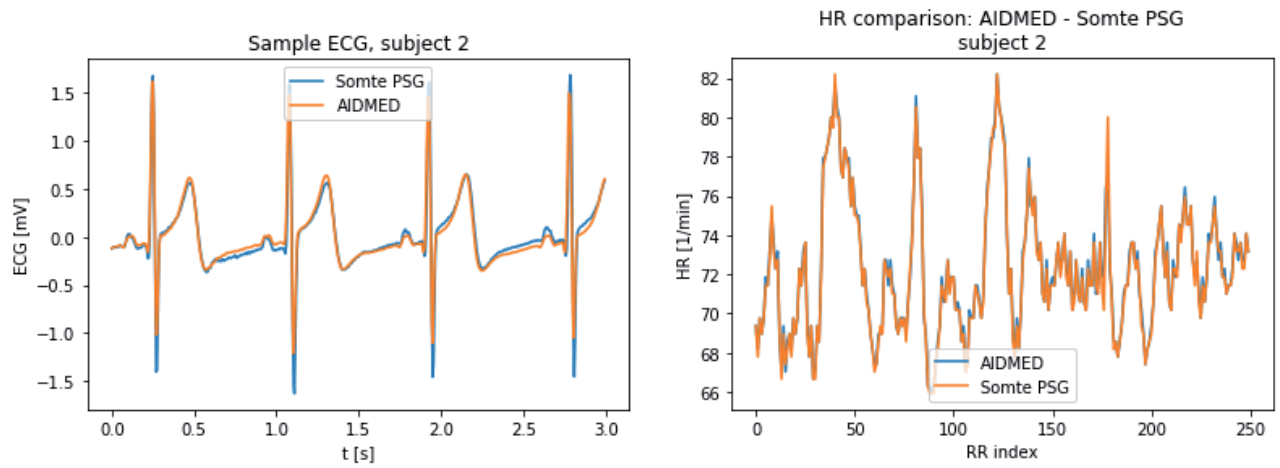

Fig. 7. Left - ECG and right - heart rate (HR) registered from volunteers: examples of signal comparison.

Source: own research

\section{Discussion}

Physiological monitor mounted on a chest strap, equipped with a set of sensors was found to be reasonably comparable with professional equipment (Alice One night, Somte PSG) which need professional settings to be used. Other sensors such as blood oxygen saturation $\left(\mathrm{SPO}_{2}\right)$ and body temperature, body position have been also validated in laboratory setup. Cough detection is still in the developing/experimental stage. The system is providing near real-time monitoring of patients via safe Internet connection, which is not a case for current standards of care. Interactive Telemedicine requires some new techniques (as task manager by Aidmed Health and teleconsultations by medical providers) within "patientcentered" paradigma. The use of AIDMED solutions can be implemented both on:

- an individual (for example personalised schedule of tasks, because our system is flexible which is not available in competitive solutions); 
- an institutional level (for example in massive screening among populations at-risk such as some specific workers, elederly, etc. (Grabowski, 2020), because many more patients can be investigated compared with standard in occupational health).

Some first patients were using the AIDMED system in production state already and they appreciated the "patient-oriented care" of such a system (Cartwright, et al., 2013) in multiple possible (presented below) applications.

\section{Cardiology}

There are many devices used for ECG recording which are designed or may be adapted to telemedical applications (Fung, at al., 2015). It is worth mentioning QardioCore C100, KardiaMobile and SEEQ MCT provide wireless data transmission. Advantage of AIDMED is that ECG is additional to other measurements.

\section{Pulmonology}

Most devices designed for APNEA, Home Sleep Test Type 3 devices since they acquire an adequate set of signals, do not support wireless communication. As an exception we can point on the InfoScan MED 350 Recorder.

\section{Functional physiological tests}

Exercise induced physiological response is a great tool in assessing general health status. 6 min walk and variants of sit-to-stand tests are widely used to assess health status of older people (van Lummel, 2016), patients with COPD and other pulmonary diseases (Meriem., 2015; Briand, 2018; Ozalevli, 2007). It was observed that instrumented exercises have greater clinical relevance (van Lummel, 2016). AIDMED ONE is unobstructive and allows data acquisition during exercises. It contains an accelerometer which enables automated repetition counting, monitoring patient adherence for exercise guidelines and in detail analysis of movement patterns. For instance patients using AIDMED can not only perform a given physical exercise on a given time, but are asked to fill forms in various stages of the test as mMRC scale (a self-rating for breathlessness) for better diagnostic power of the test. We do not know other medical devices which provide similar functionality.

\section{COVID-19}

Examples of devices and discussion of their maturity in following areas: respiratory assessment, cardiovascular evaluation, clinical symptom monitoring (Ding, et al 2020), has been raised due to acute and post COVID-19. The depicted landscape seems to be very fragmented and requires an additional technological layer for integration of signals gathered from different devices and different vendors, however AIDMED provides most of the needed functionalities integrated in one device. It may be used in evaluation of complex post-COVID or standard pulmonological rehabilitation (Vaidya, 2016). Integration of multiple signals describing pulmonary and cardiological state of patient, activity monitoring, user tasks and online data transmission make AIDMED system an universal tool for telemedical application. 
At-risk population (such as older adults)

Therefore, it is not important to monitor patients' health status by means of biosignals but such information should be supported with the symptoms patients are experiencing (AIDMED has such a functionality see Figure 2) to build proper scoring systems. Thus, patient monitoring supported with a human component in terms of interaction with the app (not available in other solutions) has been shown to improve outcomes (Tang, Smith, 2016). Before pandemic, socioeconomic status and health e-literacy were identified as a barrier (Beier, Kocher, Roy, 2020) for at-risk and vulnerable groups (as erderly population of patients). We hope that AIDMED allows seniors to access telemedicine to a higher extent and enables the democratisation of health care in middle income countries such as Poland. AIDMED system was designed to be user friendly (and is continuously adapting to the needs). Demand for such a simple, but validated (as we provided here) telehealth services is increasing (Bonted, et al., 2020). An important part of telemedicine is communication between patient and doctor. Besides vital signal acquisition, there is a need for monitoring subjective health status and its change, providing feedback and encouraging rehabilitation (in case it is possible). All that may be done with user tasks available in AIDMED HEALTH. As the AIDMED team puts a strong emphasis on usability by the patient, we expect an active approach of patient's health management and more beneficial health behaviour as patients can see some real-time signals and get interpretation form a doctor or health specialists.

\section{Conclusions}

The implementation of telemonitoring physiological recording and scoring (e.g. diagnostic) system with use of mobile application (as AIDMED) make it possible:

- to monitor remotely patients' health condition which provides the opportunity to improve healthcare and cooperation with patients;

- to manage secondary prevention of chronic diseases;

- for early detection of pathological decompensation in patients suffering from unspecific or mild symptoms, due to use of multiple sensors and questionnaires;

- to relieve healthcare system overload, reduce the number of traditional followup visits and, to some extent, optimise the use of limited health care resources (mainly physicians);

- to increase democratisation of medical processes and self-control of patientbased measurements leading to increase in quality of life and satisfaction of the patients;

- to provide diagnostic accuracy of home/remote-based at the same level as in out-patients settings.

ICT (online) solutions in the field of e-health, telemedicine and modern devices diagnostic services are crucial in providing medical services beyond their traditional environment. Easy to use, portable, integrated with smartphones (for Internet transmission and communication with medical personnel) for delivering diag- 
nostics at the point of care could lead to filling the gaps in inequalities in access to healthcare (Hernández-Neuta, et al., 2019). We believe that changes occurring in health care due to the COVID-19 global pandemic will cause telehealth to be more and more involved in medical practice and become standard of care soon. The main advantage of the AIDMED system is the ease of use as well as it could be used in the wide area of development of modern methods of acquisition of vital signs of the user and advanced methods of intelligent interpretation of medical data for the needs of telemedicine (e.g. COVID-19, Sleep-disordered breathing. arrhythmia, COPD), telerehabilitation (e.g. using gamification) or clinical research (e.g. occupational health screening). This opens up a possibility for a more reliable route to home-based identification of deterioration in at-risk patient groups in early stages of disease (secondary prevention). Moreover, we are going to use artificial intelligence methods combined with remote observation which will help in the assessment of a patient's condition, screening for diseases, and identifying patients who could develop a severe form of disease.

Funding. This work was partially funded by the Polish Agency for Medical Research 2020/ABM/COVID19/0082

\section{REFERENCES}

[1] Beier, D., Kocher, B., \& Roy, A. (2020, July 23). Ten Actions For Better Post-Pandemic Health Care In The United States. HealthAffairs. https://www.healthaffairs.org/do/ 10.1377/hblog20200721.737295/full/

[2] Bonten, T. N., Rauwerdink, A., Wyatt, J. C., Kasteleyn, M. J., Witkamp, L., Riper, H., ... \& EHealth Evaluation Research Group. (2020). Online guide for electronic health evaluation approaches: Systematic scoping review and concept mapping study. Journal of medical Internet research, 22(8), e17774. https://doi.org/10.2196/17774

[3] Briand, J., Behal, H., Chenivesse, C., Wémeau-Stervinou, L., \& Wallaert, B. (2018). The 1-minute sit-to-stand test to detect exercise-induced oxygen desaturation in patients with interstitial lung disease. Therapeutic Advances in Respiratory Disease, 12. https:// doi.org/10.1177/1753466618793028

[4] Cartwright, M., Hirani, S. P., Rixon, L., Beynon, M., Doll, H., Bower, P., ... \& Newman, S. P. (2013). Effect of telehealth on quality of life and psychological outcomes over 12 months (Whole Systems Demonstrator telehealth questionnaire study): nested study of patient reported outcomes in a pragmatic, cluster randomised controlled trial. Bmj, 346(7897), f653. https://doi.org/10.1136/bmj.f653

[5] Cobo, A., Villalba-Mora, E., Pérez-Rodríguez, R., Ferre, X., Escalante, W., Moral, C., \& Rodriguez-Mañas, L. (2020). Automatic and Real-Time Computation of the 30-Seconds Chair-Stand Test without Professional Supervision for Community-Dwelling Older Adults. Sensors, 20(20), 5813. https://doi.org/10.3390/s20205813

[6] Czekaj, Ł., Daniszewski, M., \& Domaszewicz K. (2020). Validation of the Aidlab solution for measuring Heart Rate Variability. Aidlab. https://www.aidlab.com/static/downloads / aidlab_hrv_validation_white_paper.pdf

[7] Ding, X., Clifton, D., Ji, N., Lovell, N. H., Bonato, P., Chen, W., Yu, X., Xue, Z., Xiang, T., Long, X., Xu, K., Jiang, X., Wang, Q., Yin, B., Feng, G., \& Zhang, Y. T. (2021). Wearable 
Sensing and Telehealth Technology with Potential Applications in the Coronavirus Pandemic. IEEE reviews in biomedical engineering, 14, 48-70. https://doi.org/10.1109/ RBME.2020.2992838

[8] Duplaga, M. (2019). Wsparcie telemedyczne w chorobach układu oddechowego [Telemedicine support in respiratory diseases]. Inżynieria Biomedyczna, Podstawy i Zastosowania [Biomedical Engineering, Principles and Applications], 579-597. Akademicka Oficyna Wydawnicza EXIT.

[9] Duplaga, M. (2021). The association between Internet use and health-related outcomes in older adults and the elderly: a cross-sectional study. BMC Medical Informatics and Decision Making, 21(1), 1-12. https:/ / doi.org/10.1186/s12911-021-01500-2

[10] Fung, E., Järvelin, M. R., Doshi, R. N., Shinbane, J. S., Carlson, S. K., Grazette, L. P., Chang, P. M., Sangha, R. S., Huikuri, H. V., \& Peters, N. S. (2015). Electrocardiographic patch devices and contemporary wireless cardiac monitoring. Frontiers in physiology, 6 , 149. https://doi.org/10.3389/fphys.2015.00149

[11] Grabowski, A. (2020). Virtual Reality and Virtual Environments: A Tool for Improving Occupational Safety and Health. CRC Press.

[12] Hernández-Neuta, I., Neumann, F., Brightmeyer, J., Ba Tis, T., Madaboosi, N., Wei, Q., ... \& Nilsson, M. (2019). Smartphone based clinical diagnostics: towards democratization of evidence based health care. Journal of internal medicine, 285(1), 19-39. https:// doi.org/10.1111/joim.12820

[13] Liu, L., Stroulia, E., Nikolaidis, I., Miguel-Cruz, A., \& Rincon, A. R. (2016). Smart homes and home health monitoring technologies for older adults: A systematic review. International journal of medical informatics, 91, 44-59. https:/ /doi.org/ 10.1016/j. ijmedinf.2016.04.007

[14] Meriem, M., Cherif, J., Toujani, S., Ouahchi, Y., Hmida, A. B., \& Beji, M. (2015). Sitto-stand test and 6-min walking test correlation in patients with chronic obstructive pulmonary disease. Annals of thoracic medicine, 10(4), 269-273. https://doi.org/ 10.4103/1817-1737.165289

[15] Ministry of Foreign Affairs Republic of Poland. (2020). Pro-PLUS telemedicine solution for COVID-19. Website of the Republic of Poland. https://www.gov.pl/web/diplomacy/ pro-plus-telemedicine-solution-for-covid-19

[16] Overdijkink, S. B., Velu, A. V., Rosman, A. N., Van Beukering, M. D., Kok, M., \& Steegers-Theunissen, R. P. (2018). The usability and effectiveness of mobile health technology-based lifestyle and medical intervention apps supporting health care during pregnancy: systematic review. JMIR mHealth and uHealth, 6(4), e109. https://doi.org/ 10.2196/mhealth.8834

[17] Ozalevli, S., Ozden, A., Itil, O., \& Akkoclu, A. (2007). Comparison of the Sitto-Stand Test with 6 min walk test in patients with chronic obstructive pulmonary disease. Respiratory medicine, 101(2), 286-293. https://doi.org/10.1016/j. rmed.2006.05.007

[18] Scalvini, S., Comini, L., \& Bernocchi, P. (2020). How can multidisciplinary management with remote monitoring improve the outcome of patients with chronic cardiac diseases?. Expert review of medical devices, 17(3), 153-157. https://doi.org/ $10.1080 / 17434440.2020 .1720510$

[19] Scott, J. B., \& Kaur, R. (2020). Monitoring breathing frequency, pattern, and effort. Respiratory Care, 65(6), 793-806. https://doi.org/10.4187/respcare.07439

[20] Seppä, V. P., Hyttinen, J. A., \& Viik, J. (2015). Impedance pneumography for ambulatory assessment of obstructive respiratory diseases. Ambient Intelligence and Smart Environments. Volume 20: Recent Advances in Ambient Assisted Living - Bridging Assistive 
Technologies, e-Health and Personalized Health Care, 45-62. IOS Press, Amsterdam, The Netherlands. https:// doi.org/10.3233/978-1-61499-597-5-45

[21] Tang, P. C., \& Smith, M. D. (2016). Democratization of health care. Jama, 316(16), 16631664. https://doi.org/10.1001/jama.2016.14060

[22] Taranowicz, I. (2010). Zdrowie $i$ sposoby radzenia sobie z jego zagrożeniami [Health and ways to deal with its threats]. Oficyna Wydawnicza Arboretum, Wrocław, Poland.

[23] TÜV NORD. (2021). EC Certificate. Aidmed. https://www.aidmed.ai/wp-content/ uploads/ 2021/05/AIDMED-TNP-MDD-2021-skan.pdf

[24] Radziński, Ł., Czekaj, Ł., Domaszewicz, K. (2020). Validation of Aidlab for measuring Respiratory Rate. Aidlab. https://www.aidlab.com/static/downloads/aidlab_respiratory_validation_white_paper.pdf

[25] Wong, M. Y. Z., Gunasekeran, D. V., Nusinovici, S., Sabanayagam, C., Yeo, K. K., Cheng, C. Y., \& Tham, Y. C. (2021). Telehealth demand trends during the COVID19 pandemic in the top 50 most affected countries: Infodemiological evaluation. JMIR public health and surveillance, 7(2), e24445. https://doi.org/10.2196/24445

[26] van Lummel, R. C., Walgaard, S., Maier, A. B., Ainsworth, E., Beek, P. J., \& van Dieën, J. H. (2016). The Instrumented Sit-to-Stand Test (iSTS) Has Greater Clinical Relevance than the Manually Recorded Sit-to-Stand Test in Older Adults. PloS one, 11(7), e0157968. https://doi.org/10.1371/journal.pone.0157968

[27] Vaidya, T., de Bisschop, C., Beaumont, M., Ouksel, H., Jean, V., Dessables, F., \& Chambellan, A. (2016). Is the 1-minute sit-to-stand test a good tool for the evaluation of the impact of pulmonary rehabilitation? Determination of the minimal important difference in COPD. International Journal of Chronic Obstructive Pulmonary Disease, 11(1), 26092616. https://doi.org/10.2147/COPD.S115439 